\title{
The effect of COVID-19 on the air pollution in urban areas of Pakistan
}

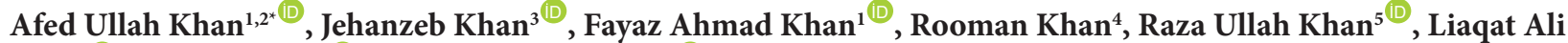 \\ Shah $^{2}{ }^{\mathbb{D}}$, Zahoor Khan ${ }^{\circledR}$, Yasir Irfan Badrashi' ${ }^{1,2}$ \\ ${ }^{1}$ National Institute of Urban Infrastructure Planning, University of Engineering and Technology Peshawar, Pakistan \\ ${ }^{2}$ Department of Civil Engineering, University of Engineering and Technology Peshawar (Bannu Campus), Bannu, Pakistan \\ ${ }^{3}$ Government Post Graduate College Kohat, Higher Education Department, Khyber Pakhtunkhwa, Pakistan \\ ${ }^{4}$ Basic Health Unit of Hakeem Bharat Bannu, Health Department Khyber Pakhtunkhwa, Pakistan \\ ${ }^{5}$ Department of Chemistry, Nanjing University of Science and Technology, Nanjing, China
}

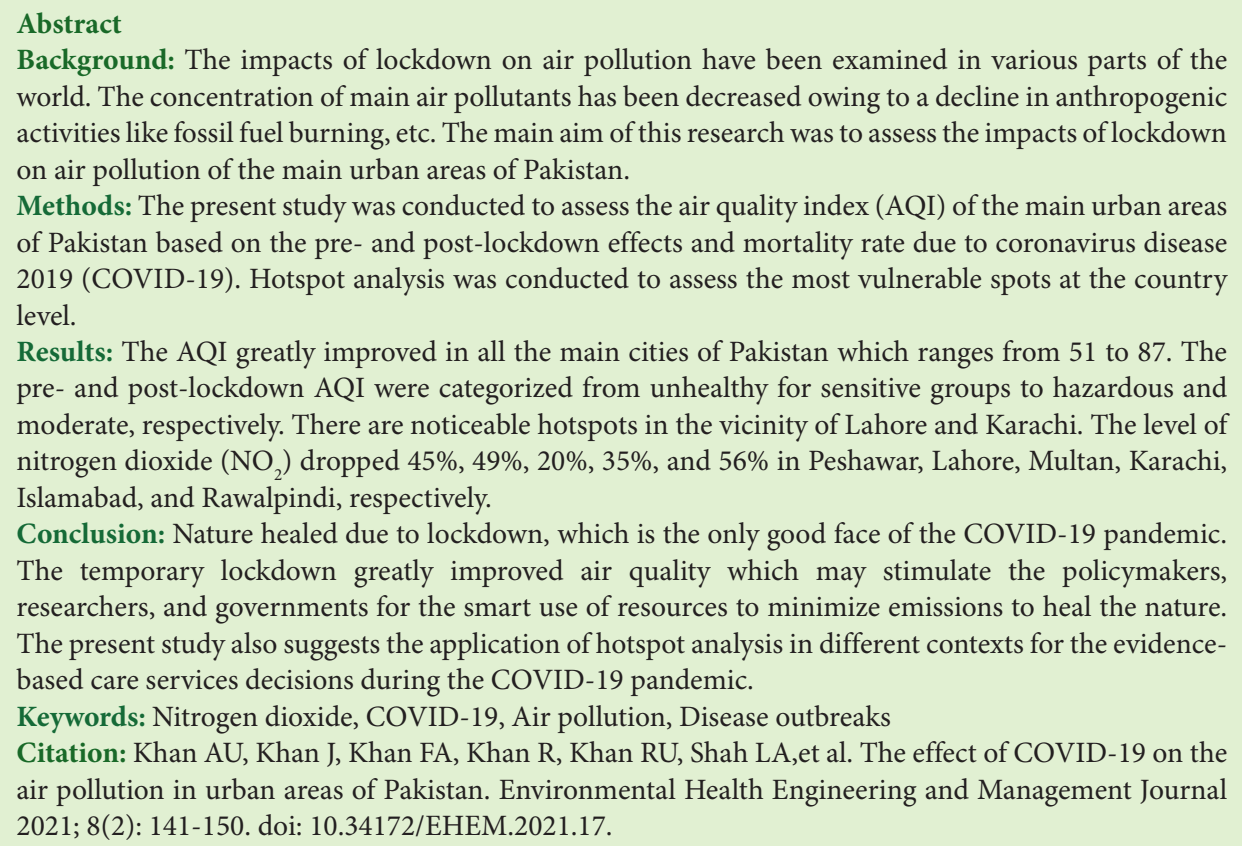
world. The concentration of main air pollutants has been decreased owing to a decline in anthropogenic activities like fossil fuel burning, etc. The main aim of this research was to assess the impacts of lockdown on air pollution of the main urban areas of Pakistan.

Methods: The present study was conducted to assess the air quality index (AQI) of the main urban areas of Pakistan based on the pre- and post-lockdown effects and mortality rate due to coronavirus disease 2019 (COVID-19). Hotspot analysis was conducted to assess the most vulnerable spots at the country level.

Results: The AQI greatly improved in all the main cities of Pakistan which ranges from 51 to 87 . The pre- and post-lockdown AQI were categorized from unhealthy for sensitive groups to hazardous and moderate, respectively. There are noticeable hotspots in the vicinity of Lahore and Karachi. The level of nitrogen dioxide $\left(\mathrm{NO}_{2}\right)$ dropped 45\%, 49\%, 20\%, 35\%, and 56\% in Peshawar, Lahore, Multan, Karachi, Islamabad, and Rawalpindi, respectively.

Conclusion: Nature healed due to lockdown, which is the only good face of the COVID-19 pandemic The temporary lockdown greatly improved air quality which may stimulate the policymakers, researchers, and governments for the smart use of resources to minimize emissions to heal the nature. The present study also suggests the application of hotspot analysis in different contexts for the evidencebased care services decisions during the COVID-19 pandemic.

Keywords: Nitrogen dioxide, COVID-19, Air pollution, Disease outbreaks

Citation: Khan AU, Khan J, Khan FA, Khan R, Khan RU, Shah LA,et al. The effect of COVID-19 on the air pollution in urban areas of Pakistan. Environmental Health Engineering and Management Journal 2021; 8(2): 141-150. doi: 10.34172/EHEM.2021.17.

\author{
Article History: \\ Received: 19 January 2021 \\ Accepted: 5 April 2021
}

ePublished: 24 June 2021

\section{Introduction}

The World Health Organization (WHO) recently declared a health emergency at global level owing to the exponential spread of infectious coronavirus disease 2019 (COVID-19). In December 2019, COVID-19 originated from Wuhan, China $(1,2)$ and badly impacted more than 100 countries within three months. The rapid spread of COVID-19 brought about consequences across the world and made itself a pandemic (2). To reduce the transmission of the virus, many countries of the world have adopted strict measures to reduce human interaction, which includes curfew, prohibiting social, cultural, educational, and religious gatherings to make sure social distancing, intradistrict and interdistrict transportation to restrict the people movement, and even, complete lockdown of the whole city. People are encouraged to perform online duties in order to reduce the spread of the virus. In many countries of the world, complete lockdown at the country level increases air quality, which is the only good face of COVID-19. In 2017, 9\% of deaths were caused by air pollution globally. This shows that air pollution is one of the leading causes of human death.

Air provides carbon dioxide $\left(\mathrm{CO}_{2}\right)$ and oxygen $\left(\mathrm{O}_{2}\right)$ for photosynthesis and respiration, respectively. Rapid industrialization and urbanization have had bad effects on the air via the introduction of hazardous gases, which are hard to inhale and making human life uncomfortable. Particulate matter $(\mathrm{PM})$ such as $\mathrm{PM}_{10}(<10 \mu \mathrm{m})$ and 
$\mathrm{PM}_{2.5}(<10 \mu \mathrm{m})$ are highly dangerous to the human when it entries into the bloodstream of human beings via lungs $(3,4)$. Respiratory infections, chronic obstructive pulmonary disease, asthma, and lung cancer are caused by air pollutants $(5,6)$. The death toll of air pollution varies from country to country ( $2 \%$ to $17.5 \%$ ) depending upon the air pollution status of the country. In $2017,9 \%$ of deaths were caused by air pollution globally. This shows that air pollution is one of the leading causes of human death. The highest rates of death from air pollution occur in low-tomiddle income countries (7). Globally, air pollution causes 7 million deaths annually via non-communicable diseases including acute respiratory infections like pneumonia (3).

In the present situation of COVID-19, scientists argued that smoking and high air pollution fuels the vulnerability to this disease $(3,8,9)$. Moreover, countries with high air pollution including China, South Korea, Iran, and northern Italy may face severe conditions of COVID-19 cases. Particularly cities with higher air pollution are more vulnerable to the COVID-19 outbreak (5,10-12). It is well-founded knowledge that high air pollution fuels the occurrence of pulmonary diseases and respiratory tract infections (13-15). Air pollution can enhance COVID-19 infections by reducing survival chances $(12,16)$.

Lockdown restricted anthropogenic activities affected the environment in a positive way. In India, particulate matter $\left(\mathrm{PM}_{2.5}\right)$ levels have been reduced to normal (40 $\mathrm{g} / \mathrm{m}^{3}$ ) and carbon monoxide (CO) concentration has also been reduced to $10 \mathrm{ppm}$ (17). In Korea, remarkable improvement was observed in the levels of $\mathrm{PM}_{2.5}, \mathrm{PM}_{10}$, $\mathrm{CO}$, and $\mathrm{NO}_{2}$ in twin cities i.e. Seoul and Daegu (18). In Kannur, south India, the concentration of VOCs (61\%), $\mathrm{CO}(67 \%), \mathrm{NH}_{3}(16 \%)$, and $\mathrm{SO}_{2}(62 \%)$ were significantly improved due to lockdown (19). In many cities of the world, $\mathrm{NO}_{2}$ concentration was significantly improved (20).

The geographic information system (GIS) is a handy tool to assess the spatial distribution of any infectious disease (17), which can assist in controlling the pandemic and enhance rapid response. GIS helps in analyzing and visualizing the COVID-19 pandemic updates via live GIS dashboard to inform people about the current situation of the pandemic i.e. number of cases, recovered patients, and mortalities. Very few GIS-based studies have been conducted on the COVID-19 pandemic. Lakhani identified the most vulnerable location of COVID-19 patients using GIS to foster the care facility in Australia (18). Gibson and Rush, used GIS to mark dwelling boundaries of probable infection spread in South Africa (19).

In February 2020, the COVID-19 pandemic reached Pakistan. To control the pandemic, the government of Pakistan has imposed strict lockdown in multiple regions in the country based on the number of COVID-19 cases. To reduce the fast pace spread of the pandemic, Pakistan has adopted strict measures to decrease the effects of the virus by curfew, prohibiting social, cultural, educational, and religious gathering to reduce human interaction, interdistrict and intradistrict transportation to restrict people movement, and even, complete lockdown of the whole city. Union council (UC) having positive COVID-19 cases was closed for all kinds of activities for at least 14 days until the condition become normal (no cases of COVID-19 after retesting the patients). The main aims of the present study were to identify the most vulnerable spots in Pakistan using hotspot analysis, to assess the impact of lockdown on spatial and temporal variations on air quality index (AQI) in the main cities of the country, and finally, to evaluate pre- and post-lockdown effects on $\mathrm{NO}_{2}$ in the lower atmosphere (troposphere).

\section{Materials and Methods}

Currently, one-third of the population of Pakistan is living in urban areas and it is estimated to rise by $50 \%$ in 2025 . The present study was conducted on the large cities of Pakistan including Islamabad (capital), Karachi (Sindh), Lahore (Punjab), and Peshawar (Khyber Pakhtunkhwa) as demonstrated in Figure 1. According to census report in 2017, the population of Islamabad, Karachi, Lahore, and Peshawar is 1009 832, 14916 456, 11126 285, and 1970 042, respectively. Daily COVID-19-infected cases data of Pakistan were collected (20). Air quality data for the main cities of Pakistan were obtained for October, November, December, January, February, and March from the webpage: aqcin.org (AQI data were accessed on April 15, 2020).

Hotspot analysis pinpoint statistically significant spatial clusters of hot spots (high values) and cold spots (low values). The hotspot algorithm assesses every pixel and its neighbor pixels for a particular distance to cluster the pixels as hotspot, cold spot or neutral. Hotspot analysis was conducted to assess the most vulnerable spots at the country level. Monthly AQI (range: 0 to 300+; good: 0-50; moderate: 51-100; unhealthy for sensitive groups ${ }^{\star *}$ : 101150; unhealthy: 151-200; very unhealthy: 201-300; and hazardous: $301+$ ) values were computed for the main cities of Pakistan to assess variations. Later, the AQI values were symbolically presented using GIS to develop AQI spatial and temporal maps. Pre- and post-lockdown effects were assessed on $\mathrm{NO}_{2}$ in the lower atmosphere (troposphere) (21-24). The mortality rate was computed for the COVID-19 as per the method suggested by Ghani et al (25). This technique is very simple and applicable where death and recovery rate from hazard are proportional at any time " $\mathrm{t}$ " as per the data obtained from hospitals.

Mortality rate $(\%)=$ (number of deaths/number of cases $)$ $\times 100$

$=$ probability of death infected by the virus (\%) (1)

The mortality rate was compared with the death rate caused by air pollution (7). 


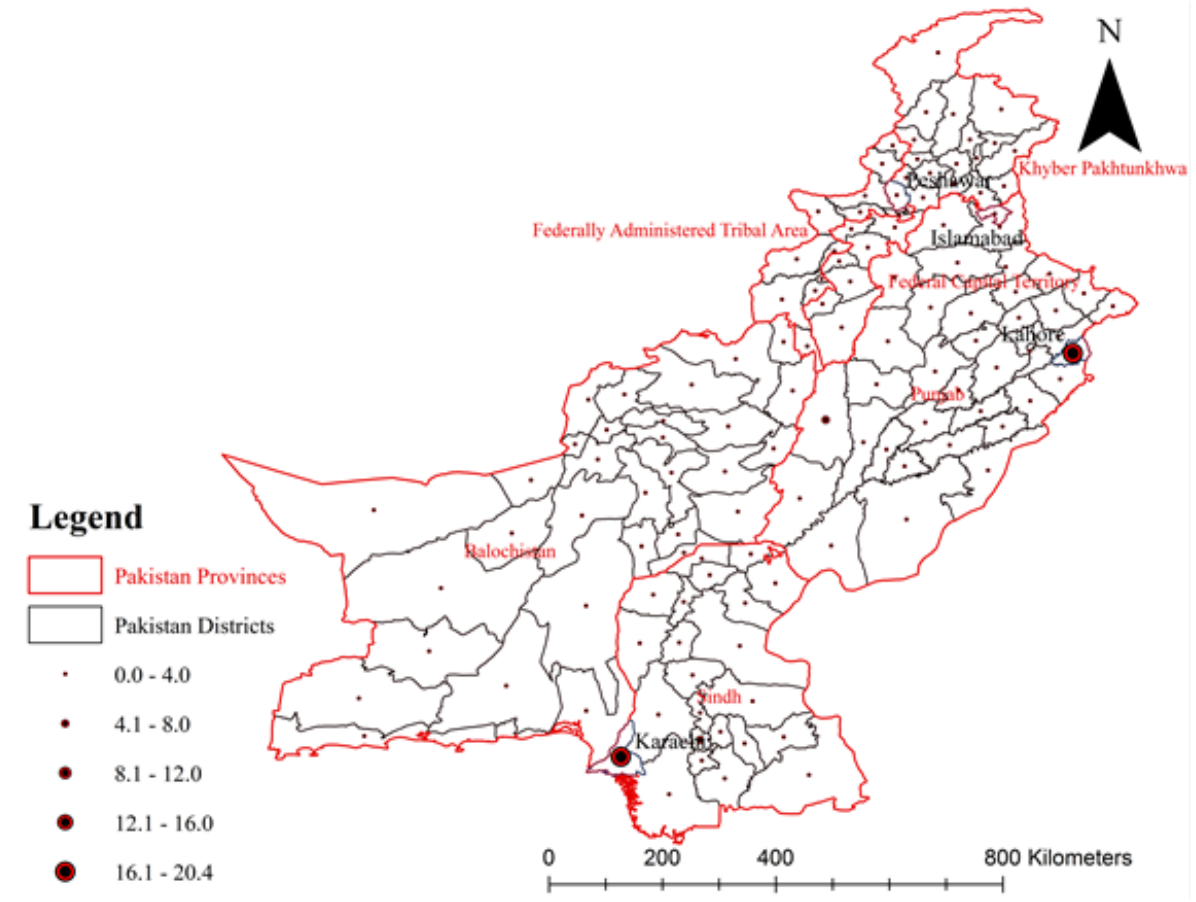

Figure 1. Study area demonstrating the main cities of Pakistan.

\section{Results}

\section{Current situation of COVID-19 in Pakistan}

More than 70000 tests were conducted at the country level where approximately 6000 cases were reported. The number of infected people is growing exponentially. 107 people were died while 1446 patients were recovered. In Pakistan, the recovery rate is higher than the death rate (Figure 2). The death rate is lower because this is the early stage of the pandemic in Pakistan. The mortality rate will increase when local transmission gain momentum.

The ratio of male cases is higher than the female cases as

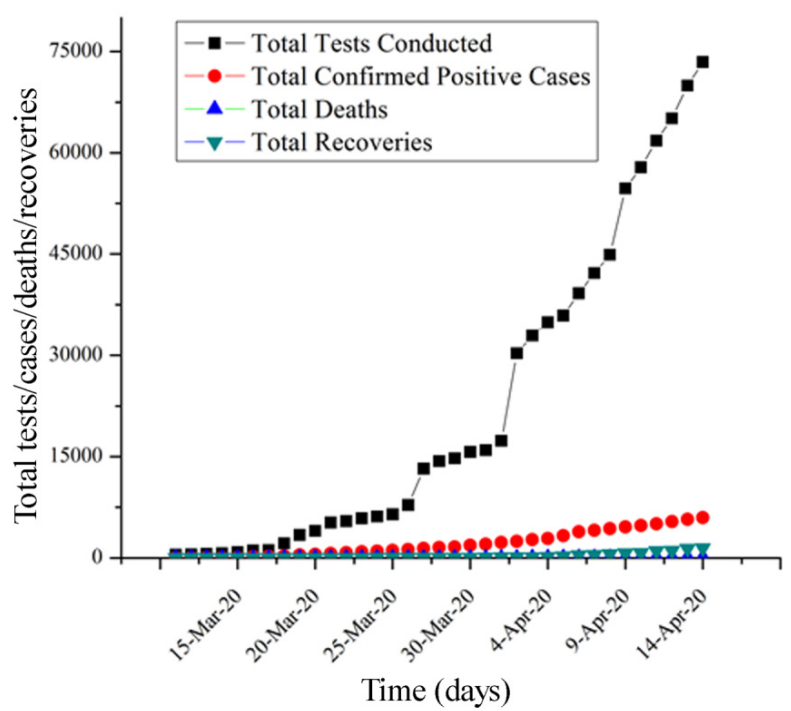

Figure 2. Brief details of the COVID-19 pandemic. shown in Figure 3. This can be due to the fact that females usually stay at home and engaged in familial activities. Due to their weak immune system, old people aged more than 50 years, are more vulnerable to the coronavirus compared to young people (26).

Figure 4 shows spatial variations in COVID-19 cases at the provincial level. Punjab and Sindh are the most vulnerable provinces to the COVID-19 pandemic. Except for these two provinces, currently, the remaining places are comparatively at a lower risk. Lahore and Karachi contain $16 \%$ to $20 \%$ of the total COVID-19-infected patients in the country, respectively, as depicted by Figure

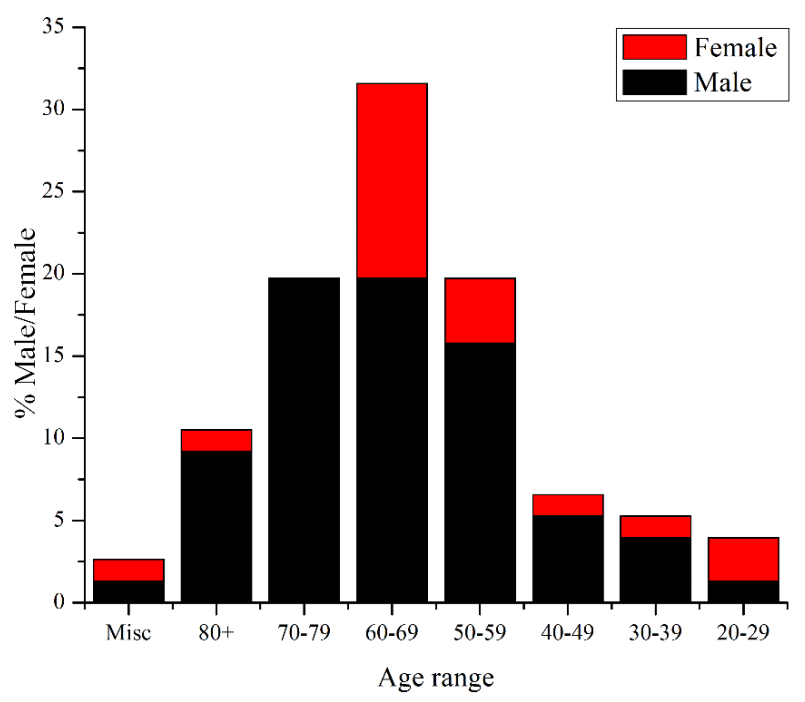

Figure 3. Distribution of COVID-19 cases by gender and age. 
1. And Hyderabad and Dera Gazi Khan contain $4 \%$ to $8 \%$ of the total COVID-19-infected patients in the country, respectively.

Identification of the most vulnerable spots at the provincial level

The results of the hotspot analysis, which considers the percentage of COVID-19-infected patients as a variable, show clustering in the studied area as shown in Figure

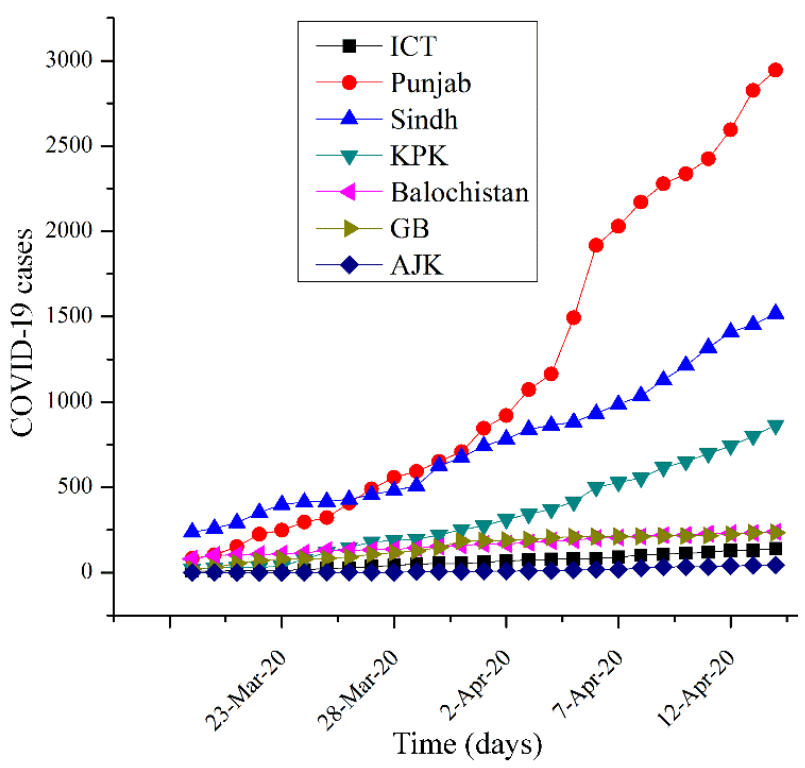

Figure 4. Spatial variations in COVID-19 cases.
5. There are very specific areas in Punjab and Sindh provinces which constitute hotspots, such as Lahore and Karachi, where there are noticeable hotspots in its vicinity. However, the results vary significantly depending on the technique used for hotspot analysis. Based on the spatial configuration, noticeable variations were occurred in the results. Fixed distance approach results in making clusters with lower statistical significance while the inverse distance squared and inverse distance techniques produce quite analogous results, making groups with higher statistical significance.

It is worth mentioning that large areas of the country are not significant, which is mainly due to the heterogeneous nature of the under-analysis variable hindering making homogeneous clusters (22-24).

\section{Temporal variations in $A Q I$}

In Pakistan, AQI shows spatial and temporal variations at the country level as demonstrated by Table 1 . The AQI showed spatial variations at the country level where the AQI of Lahore $>$ Peshawar $>$ Karachi $>$ Islamabad subjected to urbanization, industrialization, transport facilities, fuel burning, and climatic conditions, etc. Temporally, the AQI has shown greater variations in the main cities of Pakistan. Usually, the AQI values are higher in winter compared to summer. From October 2019 to February 2020, the AQI ranges from unhealthy for sensitive groups to hazardous (ranging from 106 to 315 ), as shown in Figure 6. The AQI is higher in December 2019 in almost all the main cities of Pakistan. Higher AQI causes serious respiratory

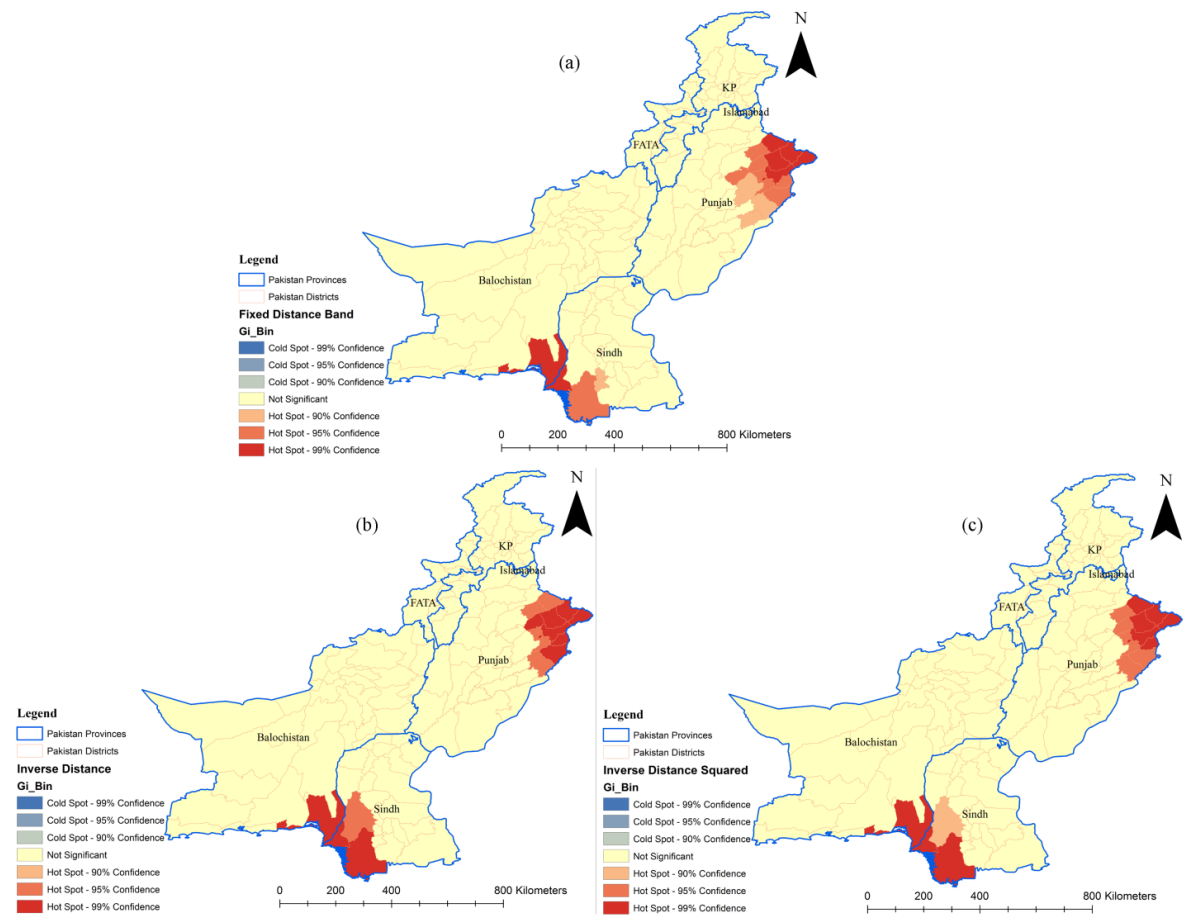

Figure 5. Hot spot analysis comparison to conceptualize spatial relationships: (a) Fixed distance band; (b) Inverse distance; (c) Inverse distance squared using Euclidean distance approach. 
Table 1. Air quality index trend

\begin{tabular}{|c|c|c|c|c|c|c|}
\hline Cities & Mar-20 & Feb-20 & Jan-20 & Dec-19 & Nov-19 & Oct-19 \\
\hline Karachi & 69 & 117 & 106 & 210 & 149 & 155 \\
\hline Lahore & 51 & 195 & 278 & 315 & 186 & 265 \\
\hline Islamabad & 67 & 167 & 129 & 190 & 160 & 111 \\
\hline Peshawar & 87 & 194 & 205 & 215 & 169 & 177 \\
\hline
\end{tabular}

effects (27). In March 2019, lockdown was imposed in all the main cities of Pakistan to control the outbreak of the pandemic of COVID-19. The only good face of COVID-19 lockdown is the improvement of AQI of all the main cities of Pakistan. The AQI was greatly improved in all the main cities of Pakistan, which ranges from 51 to 87. The pre- and post-lockdown AQI was categorized from unhealthy for sensitive groups to hazardous and moderate, respectively. Nature healed due to lockdown, which is the only good face of the COVID-19 pandemic outbreak (28).

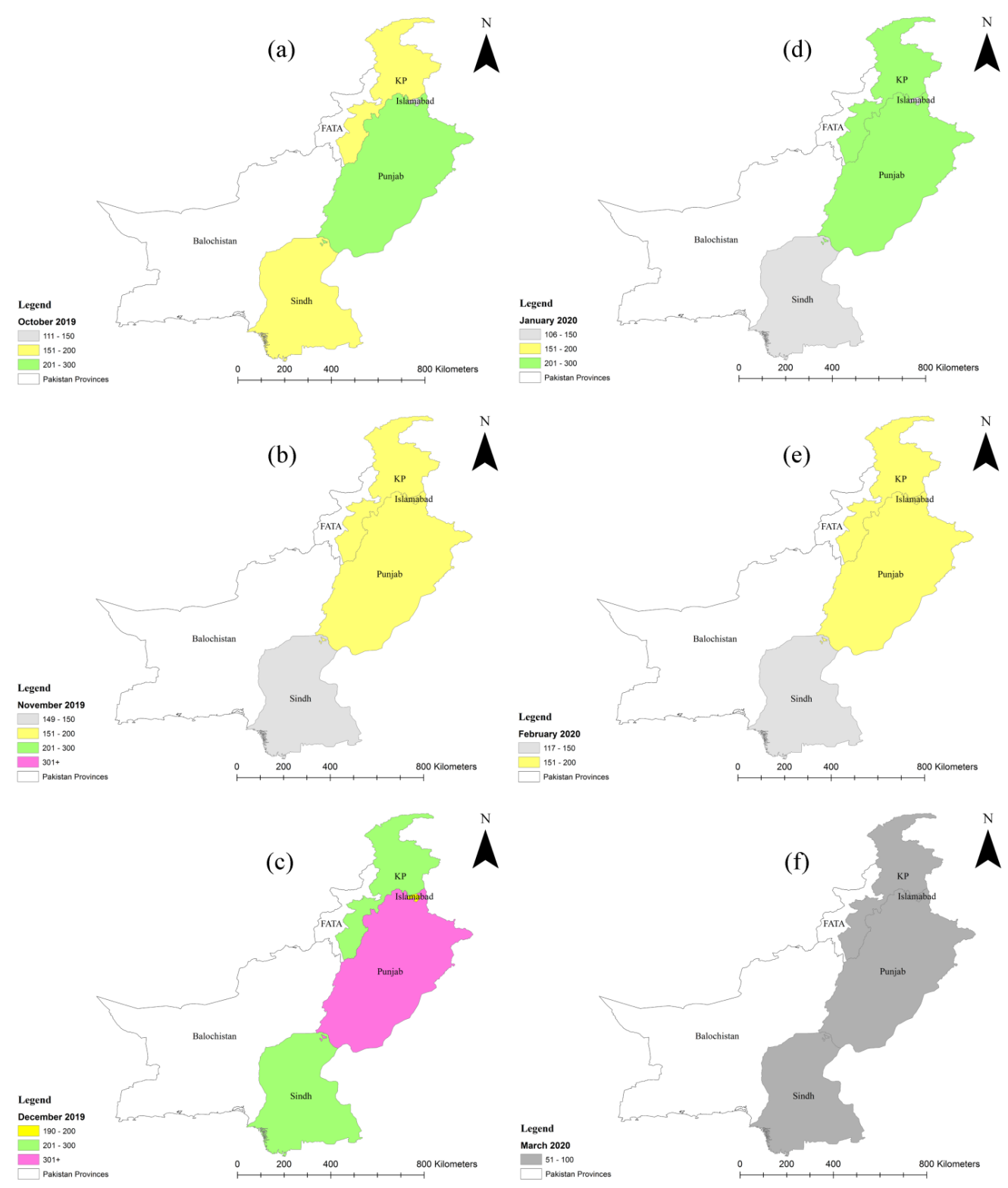

Figure 6. Temporal variation in the AQI in Islamabad, Khyber Pakhtunkhwa, Punjab, and Sindh: (a) October; (b) November; (c) December; (d) January; (e) February; and (f) March. 


\section{Comparative assessment of mortality rate}

The mortality rate was computed using the formula suggested by Ghani et al (25). The mortality rate of COVID-19 is increasing with each passing day. Currently, the mortality rate is below $2 \%$ at the country level (Figure 7). Moreover, the mortality rate of COVID-19 was compared with that of other virus-borne diseases. Generally, the mortality rate of severe acute respiratory syndrome (SARS) and Middle East respiratory syndrome (MERS) was comparatively higher than that of COVID-19 (29). The result may change because COVID-19 is in the initial stage in Pakistan and far from over.

In Pakistan, air pollution caused $9.04 \%$ of deaths in 2017. On a global scale, mortality rate varies from $2 \%$ to $15 \%$ by country as shown in Figure 8 (7). Due to this, air pollution is considered as one of the main death tool for human beings. Currently, mortality rate of air pollution is higher than COVID-19 in Pakistan. Globally, each year 7 million people die because of air pollution via

(a)

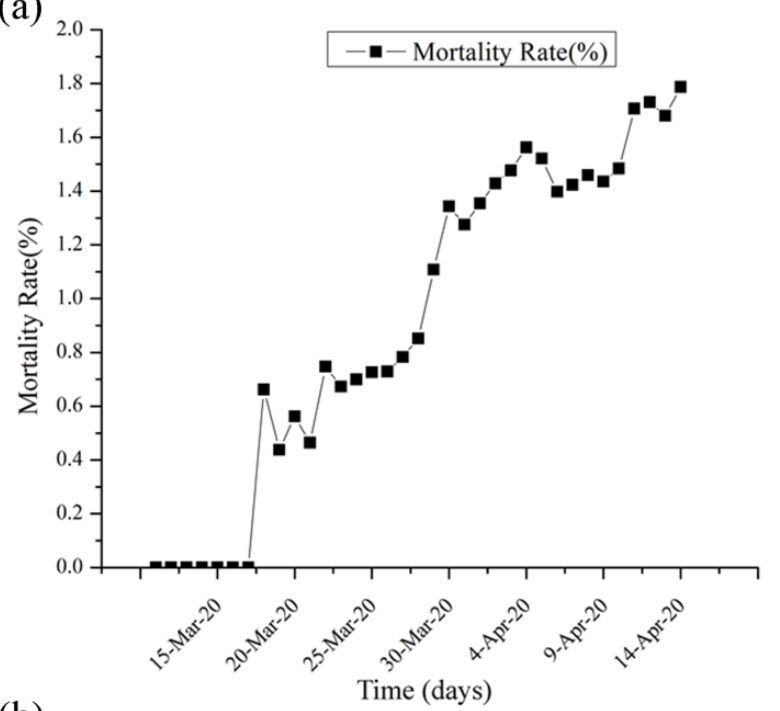

(b)

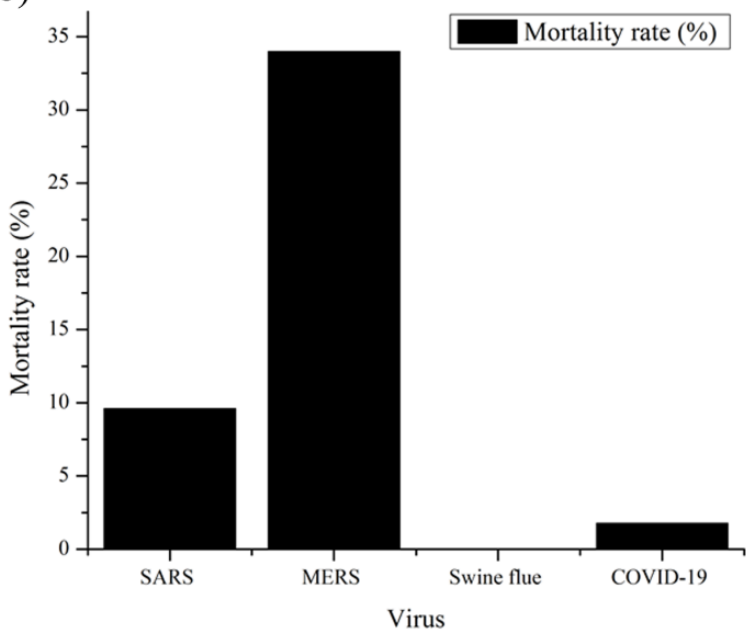

Figure 7. Mortality rate of various virus-borne diseases. (a) COVID-19 in Pakistan; (b) Other diseases (28). non-communicable diseases including acute respiratory infections (3).

$\mathrm{NO}_{2}$ drop down in the key cities of Pakistan pre- (0103-2020 to 23-03-2020) and post- (24-03-2020 to 15-042020) lockdown

COVID-19 pandemic has forced the government of Pakistan to restrict or halt interdistrict and intradistrict transportation, and industrial as well as agricultural activities at the country level. These measures were adopted to break coronavirus spread and save human lives. These measures badly impacted the socioeconomic activities of Pakistani people. The South Asian countries, Pakistan, India, and Bangladesh have the worst air quality (7). Over the past few weeks, air quality was greatly improved in Pakistan owing to a considerable reduction in fossil fuel and coal consumption in various sectors including public transport, power plants, and industries, etc. $(29,30)$. Pakistan is a real-time ambient air quality data scarce country. In the absence of the data, it is extremely hard to assess the impacts of interventions or policy decisions on the AQI and public health. Advances in remote sensing technology have made it convenient for scientists to assess air quality with or without publicly available ground monitoring stations data. The lockdown for few weeks in the main cities of Pakistan including Peshawar, Lahore, Multan, Karachi, Islamabad, and Rawalpindi showed a decrease in $\mathrm{NO}_{2}$ levels. $\mathrm{NO}_{2}$ levels reduced 45\%, 49\%, $20 \%, 35 \%$, and $56 \%$ in Peshawar, Lahore, Multan, Karachi, Islamabad, and Rawalpindi, respectively (Figure 9). In Pakistan, the national lockdown has started on March 24, 2020. Some maps are being acquired which are plotted using TROPOMI-Sentinel-5P satellite data (Figure 9). Pre- (March 1-23, 2020) and post- (March 24 to April 15, 2020) lockdown images show a decrease in $\mathrm{NO}_{2}$ levels across the main cities of Pakistan. $\mathrm{NO}_{2}$ is mainly injected into the atmosphere via burning of fuels for running transport, industries, and power plants (31-33). These activities are banned owing to the nationwide lockdown, which drastically reduced emissions.

Two hotspots, Lahore-Sheikhupura road and Raiwind to Pattoki belt, are clearly visible around Lahore before the nationwide lockdown, which shows a decline in the oilbased power plant operations. Similarly, satellite imagery of Karachi shows that $\mathrm{NO}_{2}$ emission has been reduced significantly. But some areas of Karachi show that few industries including Korangi-Landhi industrial areas and, fertilizer and cement plants at the Port Muhammad Bin Qasim were still in operation during the nationwide lockdown.

\section{Discussion}

Like other global cities (20), AQI has greatly improved in the main urban areas of Pakistan owing to a decline in human activities. Industrial emissions, fossil fuels burning, and traffic emissions are the main contributors 
to poor air quality in Pakistan. Figure 10 demonstrates primary energy sources in Pakistan. Air pollution is linked with energy consumption. The ongoing lockdown taught a good lesson that air pollution in south Asian regions is primarily linked with the main economic activities like industrial activities, public transport, and energy production $(16,17)$. A shift from high fossil fueldependent economy to clean energy systems is suggested. Although the present restrictions are not suggested to reduce air pollution, which brought a lot of suffering to the Pakistani people. But these testing times showed us what types of economic activities badly affect air quality.

In India, humidity, air temperature, and $\mathrm{PM}_{25}$ and carbon monoxide (CO) levels have been greatly reduced due to lockdown (17).

The results of the present study are consistent with the results of the study by Seo et al who found that $\mathrm{NO}_{2}$ emission is declined with lockdown in urban areas due to lower anthropogenic activities (18). Similarly, Venter et al and $\mathrm{Fu}$ et al reported that $\mathrm{NO}_{2}$ emission reduction was noted in COVID-19 lockdown $(16,21)$. The results of the present study suggested that $\mathrm{NO}_{2}$ emission is directly linked with anthropogenic activities like fossil fuel burning, traffic emissions, etc. The transportation ban is the main reason which has declined approximately $65 \%$ marginal changes in $\mathrm{NO}_{2}$ emissions across Pakistan. In Pakistan, poor air quality is mainly attributed to the abundance of vehicles and low fuel quality. Urban emissions are drastically declined due to a decrease in vehicular mobility during the nationwide lockdown $(34,35) . \mathrm{NO}_{2}$ is a toxic pollutant which is responsible for respiratory problems and deaths in Pakistan.

Hotspot analysis plays a vital role in identifying the most vulnerable populations for providing prompt and adequate care. It suggests that how much space (quarantine centers and isolation wards), medical equipment (ventilators and masks), and human capital (medical and paramedical staff) are required to fight against novel coronavirus pandemic (22). It also guides the government officials in imposing strict lockdown to restrict human movements as well as food supply in the most vulnerable areas. Hotspot analysis plays a leading role in spatial planning and management to control the outbreak. This spatial technique can be employed in different contexts as per the evidence-based COVID-19 pandemic for care service decisions.

\section{Conclusion}

This study reports hotspots identification and lockdown effects on the AQI in Pakistan. Air pollution is growing rapidly at the global scale and causes strong respiratory

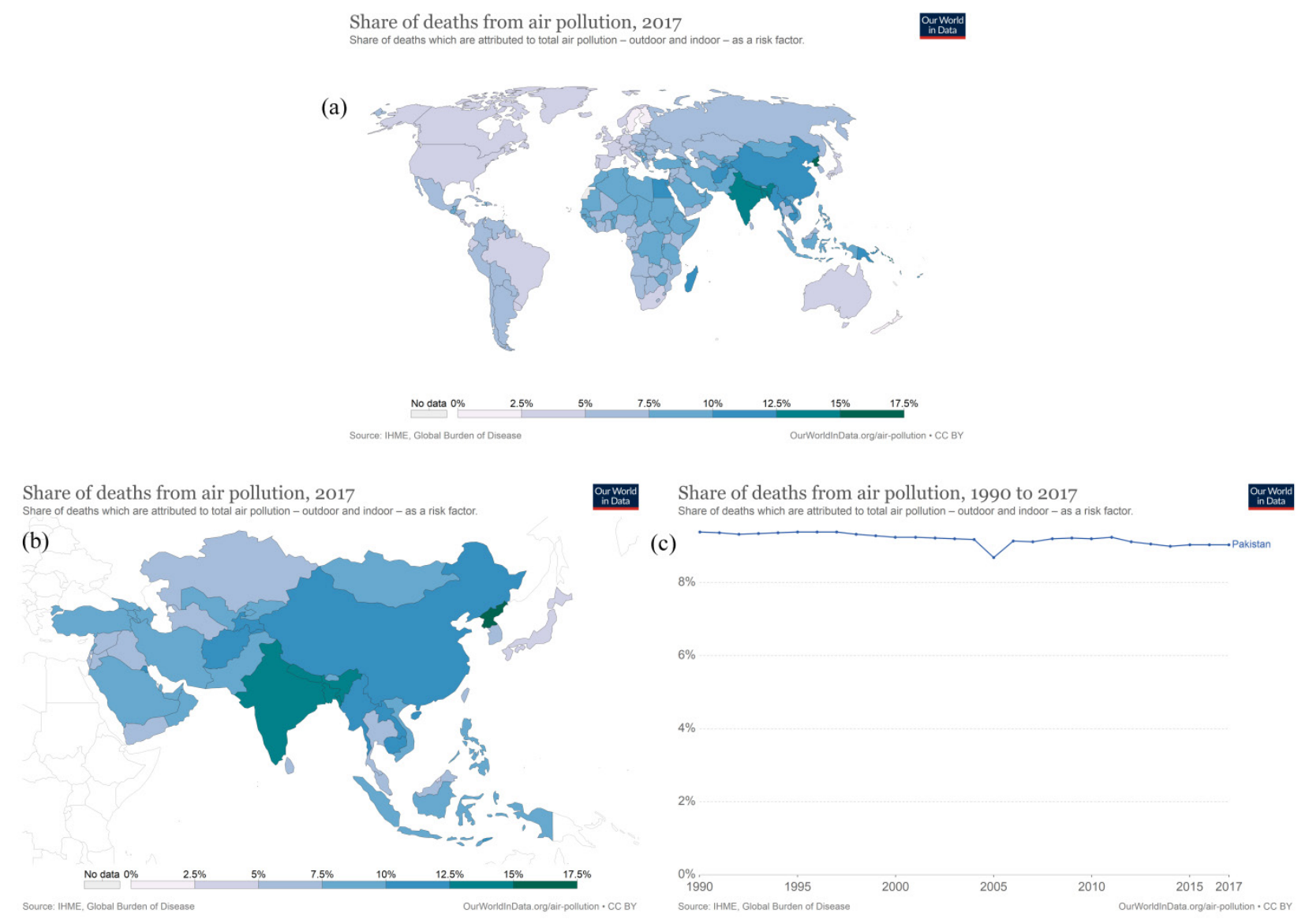

Figure 8. Maps demonstrating deaths caused by air pollution in 2017. (a) World map; (b) Asia map; (c) time series of Pakistan (3). 


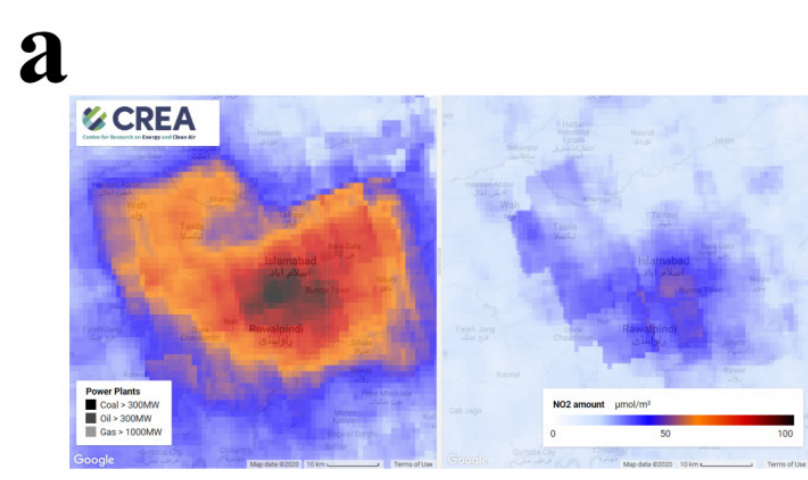

b
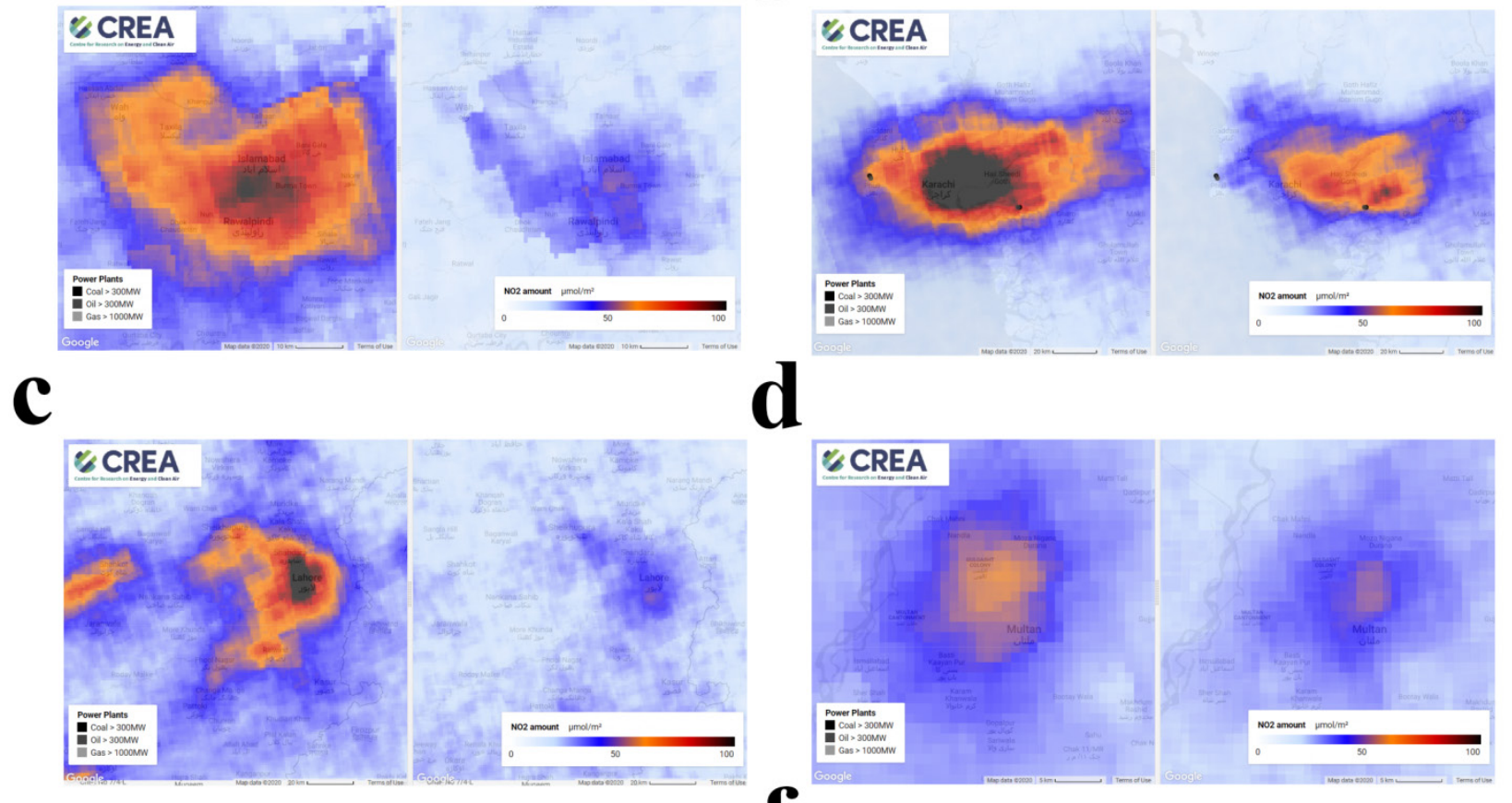

e
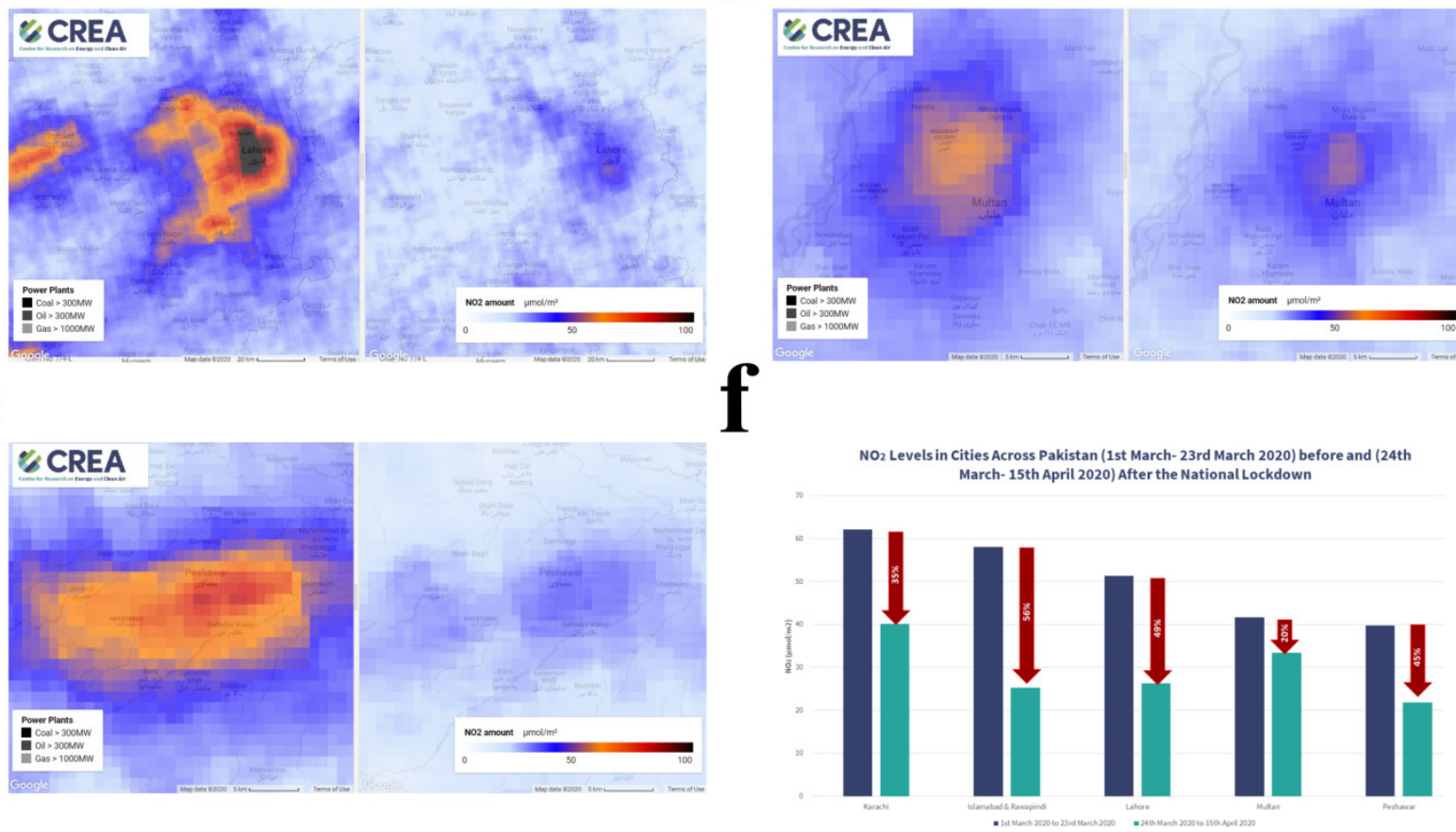

Figure 9. Pre- (March 1- 23, 2020) and post- (March 24 - April 15, 2020) drop-down in $\mathrm{NO}_{2}$ levels in (a) Islamabad and Rawalpindi, (b) Karachi, (c) Lahore, (d) Multan, (e) Peshawar, (f) $\mathrm{NO}_{2}$ dop-down (TROPOMI Sentinel-5P satellite).
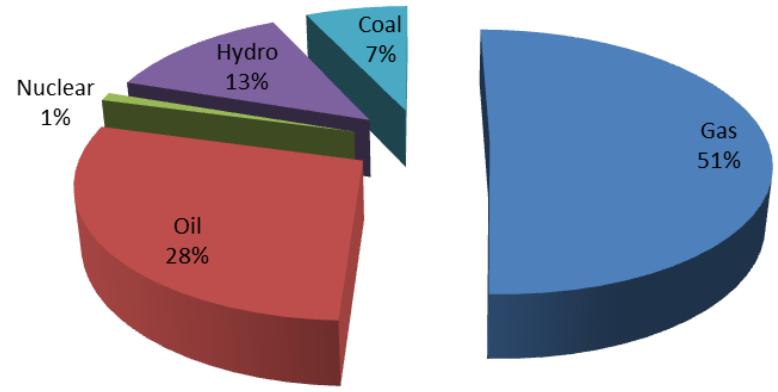

Figure 10. By source energy supply in Pakistan.

diseases in human beings. The results of hot spot analysis demonstrated that Karachi and Lahore, and their surrounding districts are the most vulnerable areas in Pakistan. The pre- and post-lockdown AQI were categorized from unhealthy for sensitive groups to hazardous, and moderate, respectively. $\mathrm{NO}_{2}$ levels dropped 45\%, 49\%, 20\%, 35\%, and 56\% in Peshawar, Lahore, Multan, Karachi, and Islamabad, and Rawalpindi, respectively. Significant improvement in air pollution was observed in Pakistan owing to the closure of industrial units and stopping of public transport at the national level. The temporary lockdown greatly improved air quality which may stimulate the policymakers, researchers, and governments for the smart use of resources to minimize emissions to heal the nature.

\section{Acknowledgments}

The authors would like to express their gratitude for the efforts made by Pakistan's COVID-19 Health Advisory Platform for providing COVID-19-related data. The authors would also like to acknowledge the TROPOMI Sentinel-5P satellite online maps data source. 


\section{Ethical issues}

The author hereby certifies that all data collected during the study are as stated in the manuscript, and no data from the study has been or will be published separately elsewhere.

\section{Competing interests}

The authors declare that they have no conflict of interests.

\section{Authors' contributions}

All authors contributed to data collection and analysis, and paper writing.

\section{References}

1. Lu R, Zhao X, Li J, Niu P, Yang B, Wu H, et al. Genomic characterisation and epidemiology of 2019 novel coronavirus: implications for virus origins and receptor binding. Lancet 2020; 395(10224): 565-74. doi: 10.1016/ S0140-6736(20)30251-8.

2. Zhu N, Zhang D, Wang W, Li X, Yang B, Song J, et al. A novel coronavirus from patients with pneumonia in China, 2019. N Engl J Med 2020; 382(8): 727-33. doi: 10.1056/ NEJMoa2001017.

3. Anjum NA. Good in the worst: COVID-19 restrictions and ease in global air pollution. Preprints 2020; 2020040069. doi: 10.20944/preprints202004.0069.v1.

4. Martelletti L, Martelletti P. Air pollution and the novel Covid-19 disease: a putative disease risk factor. SN Comprehensive Clinical Medicine 2020; 2: 383-7. doi: 10.1007/s42399-020-00274-4.

5. Conticini E, Frediani B, Caro D. Can atmospheric pollution be considered a co-factor in extremely high level of SARSCoV-2 lethality in Northern Italy? Environmental Pollution 2020; 261: 114465. doi: 10.1016/j.envpol.2020.114465.

6. Kim D, Chen Z, Zhou LF, Huang SX. Air pollutants and early origins of respiratory diseases. Chronic Dis Transl Med 2018; 4(2): 75-94. doi: 10.1016/j.cdtm.2018.03.003.

7. Hannah R, Max R. Air Pollution. Published online at OurWorldInData.org. doi: Retrieved from: https:// ourworldindata.org/air-pollution

8. Lewis T. Smoking or vaping may increase the risk of severe coronavirus infection. [cited 2020 Agu 17] Available from: https://www.scientificamerican.com/article/smoking-orvaping-may-increase-the-risk-of-a-severe-coronavirusinfection $1 /$.

9. Sharma S, Zhang M, Anshika, Gao J, Zhang H, Kota SH. Effect of restricted emissions during COVID-19 on air quality in India. Sci Total Environ 2020; 728: 138878. doi: 10.1016/j.scitotenv.2020.138878.

10. Kambalagere Y. A Study on Air Quality Index (AQI) of Bengaluru, Karnataka during Lockdown Period to Combat Coronavirus Disease (Covid-19): Air Quality Turns 'Better'from 'Hazardous'. InSpecial Issue on International Conference 2020; 40(69).

11. Sasidharan M, Singh A, Torbaghan ME, Parlikad AK. A vulnerability-based approach to human-mobility reduction for countering COVID-19 transmission in London while considering local air quality. Science of The Total Environment 2020; 741: 140515. doi: 10.1016/j. scitotenv.2020.140515.

12. Yao Y, Pan J, Wang W, Liu Z, Kan H, Meng X, et al. Spatial correlation of particulate matter pollution and death rate of COVID-19. MedRxiv 2020; doi: 10.1101/2020.04.07.20052142.

13. Cohen AJ, Brauer M, Burnett R, Anderson HR, Frostad J, Estep K, et al. Estimates and 25-year trends of the global burden of disease attributable to ambient air pollution: an analysis of data from the Global Burden of Diseases Study 2015. Lancet 2017; 389(10082): 1907-18. doi: 10.1016/ S0140-6736(17)30505-6.

14. Horne BD, Joy EA, Hofmann MG, Gesteland PH, Cannon JB, Lefler JS, et al. Short-term elevation of fine particulate matter air pollution and acute lower respiratory infection. Am J Respir Crit Care Med 2018; 198(6): 759-66. doi: 10.1164/rccm.201709-1883OC.

15. Liu Y, Pan J, Zhang H, Shi C, Li G, Peng Z, et al. Short-term exposure to ambient air pollution and asthma mortality. Am J Respir Crit Care Med 2019; 200(1): 24-32. doi: 10.1164/rccm.201810-1823OC.

16. Venter ZS, Aunan K, Chowdhury S, Lelieveld J. COVID-19 lockdowns cause global air pollution declines. Proc Natl Acad Sci U S A 2020; 117(32): 18984-90. doi: 10.1073/ pnas.2006853117.

17. Gupta N, Tomar A, Kumar V. The effect of COVID-19 lockdown on the air environment in India. Global Journal of Environmental Science and Management 2020; 6(Special Issue): 31-40. doi: 10.22034/GJESM.2019.06.SI.04.

18. Seo JH, Jeon HW, Sung UJ, Sohn JR. Impact of the COVID-19 outbreak on air quality in Korea. Atmosphere 2020; 11(10): 1137. doi: 10.3390/atmos11101137.

19. Resmi CT, Nishanth T, Satheesh Kumar MK, Manoj MG, Balachandramohan M, Valsaraj KT. Air quality improvement during triple-lockdown in the coastal city of Kannur, Kerala to combat Covid-19 transmission. Peer J 2020; 8:e9642. doi: 10.7717/peerj.9642.

20. https://covid.gov.pk/stats/pakistan (COVID-19 data were accessed on April 15, 2020).

21. Fu F, Purvis-Roberts KL, Williams B. Impact of the covid-19 pandemic lockdown on air pollution in 20 major cities around the world. Atmosphere 2020; 11(11):1189. doi: 10.3390/atmos11111189.

22. Mollalo A, Vahedi B, Rivera KM. GIS-based spatial modeling of COVID-19 incidence rate in the continental United States. Science of The Total Environment 2020; 728: 138884. doi: 10.1016/j.scitotenv.2020.138884.

23. Lakhani A. Which Melbourne metropolitan areas are vulnerable to COVID-19 based on age, disability and access to health services? Using spatial analysis to identify service gaps and inform delivery. J Pain Symptom Manage 2020; 60(1): e41-4. doi: 10.1016/j.jpainsymman.2020.03.041.

24. Gibson L, Rush D. Novel coronavirus in Cape Town informal settlements: feasibility of using informal dwelling outlines to identify high risk areas for COVID-19 transmission from a social distancing perspective. JMIR Public Health Surveill 2020; 6(2): e18844. doi: 10.2196/18844.

25. Ghani AC, Donnelly CA, Cox DR, Griffin JT, Fraser C, Lam TH, Ho LM, Chan WS, Anderson RM, Hedley AJ, Leung JM. Methods for estimating the case fatality ratio for a novel, emerging infectious disease. Am J Epidemiol 2005; 
162(5): 479-86. doi: 10.1093/aje/kwi230.

26. Lee PI, Hu YL, Chen PY, Huang YC, Hsueh PR. Are children less susceptible to COVID-19? J Microbiol Immunol Infect 2020; 53(3): 371-2. doi: 10.1016/j.jmii.2020.02.011.

27. Sterpetti AV. Lessons learned during the COVID-19 virus pandemic. J Am Coll Surg 2020; 230(6): 1092-3. doi:10.1016/j.jamcollsurg.2020.03.018.

28. Afshari R. Indoor air quality and severity of COVID-19: where communicable and non-communicable preventive measures meet. Asia Pacific Journal of Medical Toxicology 2020; 9(1): 1-2. doi: 10.22038/apjmt.2020.15312.

29. Isaifan R. The dramatic impact of Coronavirus outbreak on air quality: has it saved as much as it has killed so far? Global Journal of Environmental Science and Management 2020; 6(3): 275-88. doi: 10.22034/GJESM.2020.03.01.

30. Wu X, Nethery RC, Sabath BM, Braun D, Dominici F. Exposure to air pollution and COVID-19 mortality in the United States. MedRxiv 2020; doi: 10.1101/2020.04.05.20054502.

31. Talepour N, Hassanvand MS, Abbasi-Montazeri E,
Latifi SM, Jaafarzadeh Haghighi Fard N, Shenavar B. Identification of airborne fungi's concentrations in indoor and outdoor air of municipal wastewater treatment plant. Environmental Health Engineering and Management Journal 2020; 7(3): 142-50. doi: 10.34172/EHEM.2020.17.

32. Rahal F, Rezak S, Benabadji N. Evaluation of the impact of the COVID-19 pandemic on photochemical pollution in urban areas. Environmental Health Engineering and Management Journal 2020; 7(4): 237-43. doi: 10.34172/ EHEM.2020.28.

33. Ogen Y. Assessing nitrogen dioxide $\left(\mathrm{NO}_{2}\right)$ levels as a contributing factor to coronavirus (COVID-19) fatality. Sci Total Environ 2020; 726: 138605. doi: 10.1016/j. scitotenv.2020.138605.

34. Cadotte M. Early evidence that COVID-19 government policies reduce urban air pollution. doi: 10.31223/osf.io/ nhgj3

35. Tian H, Liu Y, Song H, Wu CH, Li B, Kraemer MU, et al. Risk of COVID-19 and long-term exposure to air pollution. MedRxiv 2020. doi: 10.1101/2020.04.21.20073700. 